\title{
Milk intake is inversely related to body mass index and body fat in girls
}

\author{
S. Abreu ${ }^{1}$, R. Santos ${ }^{1}$, C. Moreira ${ }^{1}$, P. C. Santos ${ }^{1,2}$, S. Vale ${ }^{1}$, L. Soares-Miranda ${ }^{1}$, J. Mota $^{1}$ and \\ P. Moreira ${ }^{1,3,4}$
}

(1) Research Centre for Physical Activity, Health and Leisure, Faculty of Sport, University of Porto, Porto, Portugal

(2) Department of Physical Therapy, School of Health Technology of Porto, Polytechnic Institute of Porto, Vila Nova de Gaia, Portugal

(3) Faculty of Nutrition and Food Science, University of Porto, Porto, Portugal

(4) Institute of Public Health, University of Porto, Porto, Portugal

\begin{abstract}
Dairy foods comprise a range of products with varying nutritional content. The intake of dairy products (DPs) has been shown to have beneficial effects on body weight and body fat. This study aimed to examine the independent association between DP intake, body mass index (BMI), and percentage body fat $(\% \mathrm{BF})$ in adolescents. A cross-sectional, school-based study was conducted with 1,001 adolescents (418 boys), ages 15-18 years, from the Azorean Archipelago, Portugal. Anthropometric measurements were recorded (weight and height), and \%BF was assessed using bioelectric impedance analysis. Adolescent food intake was measured using a self-administered, semiquantitative food frequency questionnaire. Data were analyzed separately for girls and boys, and separate multiple linear regression analysis was used to estimate the association between total DP, milk, yogurt, and cheese intake, BMI, and \% BF, adjusting for potential confounders. For boys and girls, respectively, total DP consumption was $2.6 \pm 1.9$ and $2.9 \pm 2.5$ servings/day $(\mathrm{P}=0.004)$, while milk consumption was $1.7 \pm 1.4$ and $2.0 \pm 1.7$ servings/day $(\mathrm{P}=0.001)$, yogurt consumption was $0.5 \pm 0.6$ and $0.4 \pm 0.7$ servings/day $(\mathrm{P}=0.247)$, and cheese consumption was $0.4 \pm 0.6$ and $0.5 \pm 0.8$ servings/day $(\mathrm{P}=0.081)$. After adjusting for age, birth weight, energy intake, protein, total fat, sugar, dietary fiber, total calcium intake, low-energy reporters, parental education, pubertal stage, and physical activity, only milk intake was negatively associated with BMI and \%BF in girls (respectively, girls: $\beta=-0.167, \mathrm{P}=0.013$; boys: $\beta=-0.019, \mathrm{P}=0.824$ and girls: $\beta=-0.143, \mathrm{P}=0.030$; boys: $\beta=-0.051, \mathrm{P}=0.548$ ). Conclusion: We found an inverse association between milk intake and both $\mathrm{BMI}$ and \%BF only in girls.
\end{abstract}

Keywords

Dairy products; Milk Body; mass index; Body; fat; Adolescents

\section{Introduction}

The increasing prevalence of overweight and obesity among children and adolescents has been described in developed and developing countries alike [60]. In the European Union, the prevalence of childhood overweight and obesity is approximately $25 \%$, with Southern European countries showing the highest prevalence rates [25, 57]. Indeed, in Portugal, $21.6 \%$ of girls and $23.5 \%$ of boys, ages 10 to 18 years, are overweight or obese [44]. Furthermore, according to some studies, more than $60 \%$ of overweight/obese adolescents tend be obese as adults [19, 39]. Obesity also has profound public health implications, being associated with increased risk of such chronic conditions as diabetes and cardiovascular disease and with high health care costs [34]. 
Obesity is a complex, multifactorial disease; however, the primary cause is related to the energy imbalance that results from low physical activity (PA) and inadequate nutrition [14, 29]. In recent years, increasing attention has been focused on the preventive effects of dairy product (DP) intake. However, there is conflicting evidence regarding the relationship between DP intake and obesity. Some observational studies of children and adolescents have reported a significant inverse relationship between dairy consumption and measures of body composition $[1,17,31$, $37,38]$, while others have found no association [2, 23, 36]. Several mechanisms have been proposed to explain how DP intake influences fatness and body composition. Although calcium was mentioned as a principal bioactive component of DPs, with effects on adipocyte lipid metabolism, other constituents such as proteins (in particular, whey proteins) and their peptide derivatives may affect body weight by regulating food intake and appetite [16].

The purpose of this study was to examine the independent association between DP intake, body mass index (BMI), and percentage body fat (\%BF) after taking into account dietary factors, physical activity level (PAL), and other potentially confounding variables in a sample of Portuguese adolescents.

\section{Materials and methods}

Sampling

Data for the present cross-sectional study were derived from a longitudinal school-based study-The Azorean Physical Activity and Health Study II, which aimed to evaluate PA, physical fitness, overweight/obesity prevalence, dietary intake, health-related quality of life, and related factors in 15- to 18-year-old adolescents. This study was carried out in six of the nine Azorean Islands (S. Miguel, Terceira, Faial, Pico, S. Jorge, and Graciosa), where $95 \%$ of the Azorean population lives [24].

All participants in this study were informed of its goals, and the parent or guardian of each participant provided written informed consent. The study was approved by the Faculty of Sport, University of Porto and the Portuguese Foundation for Science and Technology Ethics Committee; it was conducted in accordance with the World Medical Association's Helsinki Declaration for Human Studies.

The population was selected by means of proportionate stratified random sampling, taking into account location (island) and number of students, by age and sex, in each school. The estimated number of subjects needed was 1,422 , but in order to prevent information loss, data were collected for 1,515 adolescents. Some adolescents were not included in our analysis $(n=514)$ because information was missing on their dietary intake $(n=286), \operatorname{BMI}(n=15), \% B F(n=15)$, and birth weight $(n=198)$. This resulted in a collection of data for a total of 1,001 participants (418 boys). The subjects who were excluded from this study did not significantly differ from those who were included, with regard to age (16.2 \pm 1.0 vs. $16.1 \pm 1.0$ years, $P=0.118)$, parental education ( $8.8 \pm 4.4$ vs. $9.2 \pm 4.4$ years, $P=0.219$ ), gender (girls, 60.3 vs. $58.2 \%$ and boys, 39.7 vs. $41.8 \%, \mathrm{P}=0.471)$, and $\mathrm{BMI}\left(22.9 \pm 4.1\right.$ vs. $\left.22.9 \pm 3.9 \mathrm{~kg} / \mathrm{m}^{2}, \mathrm{P}=0.888\right)$. Finally, the sample was weighted, so as to balance it in accordance with the distribution of the Azorean population in schools and to guarantee the real representativeness of each group (age and gender).

\section{Anthropometric measures}

Body height and body weight were determined using standard anthropometric methods. Height was measured to the nearest millimeters in bare or stocking feet, with adolescents standing upright against a Holtain portable stadiometer (Crymych, Pembrokeshire, UK). Weight was 
measured to the nearest $0.10 \mathrm{~kg}$, with participants lightly dressed (underwear and T-shirt) and with the use of a portable digital beam scale (Tanita Inner Scan BC 532, Tokyo, Japan).

BMI was calculated using the ratio of weight/height ${ }^{2}$ (in kilograms per square meter). Subjects were classified as normal weight, overweight, or obese, according to age- and sex-specific cutoff points specified by the International Obesity Task Force $[10,11]$. Underweight subjects (2.8\%) were combined with normal weight subjects due to the fact that they represented a small proportion of the sample. \%BF was assessed using bioelectric impedance analysis-BIA (Tanita Inner Scan BC 532, Tokyo, Japan).

\section{Pubertal stage}

To determine pubertal stage (which ranged from 1 to 5), each subject was asked to self-assess his/her stage of development of secondary sex characteristics. Breast development in girls and genital development in boys was evaluated according to criteria outlined by Tanner and Whitehouse [50].

Sociodemographic and lifestyle variables

Participants answered a questionnaire that assessed several sociodemographic and lifestyle variables.

Smoking

Participants were classified as nonsmokers, former smokers (individuals who had stopped smoking for at least 6 months), occasional smokers (individuals who smoked, on average, less than one cigarette a day), and current smokers (individuals who smoked at least one cigarette a day) [59]. Occasional smokers were recoded and combined with current smokers due to the fact that they represented a small proportion of the sample.

\section{Parental education}

For the present study, the highest level of parental education (measured by the number of school years completed) was used as a proxy measure of socioeconomic status. Participants were divided into three categories, reflecting divisions within the Portuguese educational system: mandatory or less ( $\leq 9$ school years), secondary (10 to 12 school years), and college/university.

Dietary intake

Dietary intake was measured via a self-administered semiquantitative food frequency questionnaire (FFQ) that covered the previous 12 months and included 86 food item and beverage categories, validated for Portuguese adolescents [41]. This semiquantitative FFQ was designed in accordance with criteria laid out by Willett et al. [58] and adapted to include a variety of typical Portuguese food items. For each item, the questionnaire offered nine frequency response options, ranging from "never" to "six or more times per day," and measured portion size and seasonality. Any foods not listed in the questionnaire could be listed by participants in a free-response section. Energy and nutritional intake were estimated with regard to respondents' ratings of the frequency, portion, and seasonality of each item, using the software Food Processor Plus (ESHA Research Inc., Salem, OR, USA). This program uses nutritional information from the USA that has been adapted for use with typical Portuguese foods and beverages.

DPs were defined according to the new Portuguese food wheel guide [42]. The amounts of milk (whole, reduced-fat, and fat-free), yogurt, and cheese (cottage and cream cheese) that counted as single servings were considered to be $250 \mathrm{ml}, 200 \mathrm{~g}$, and $40 \mathrm{~g}$, respectively. 
Physical activity

PA was assessed via a self-report questionnaire that evaluated leisure times physical activities [52]. This questionnaire has been shown to have good test-retest reliability among Portuguese adolescents (intraclass correlation coefficient, 0.92-0.96) [33]. From this questionnaire, a summative index (range, 5-20) was derived. Participants whose scores were greater than 12.5 points were classified as active, while those whose scores were 12.5 points or less comprised the low-activity group.

\section{Statistical analysis}

Data were analyzed separately for girls and boys. The Kolmogorov-Smirnov test was used to assess the assumption of normality. Independent sample $t$ test or Mann-Whitney test were performed to compare continuous variables between gender, and the chi-square test was used with categorical variables. In this report, descriptive analysis is presented in terms of means and standard deviations.

To access associations between $\mathrm{DP}$ and $\mathrm{BMI}$ and \%BF, we performed separate regression linear models for each DP: total dairy, milk, yogurt, and cheese. For each DP, we adjusted linear regression model for age (in years), birth weight (in kilograms), energy intake (in kilocalories), total calcium intake (in milligrams), protein intake (in grams per kilogram of weight), sugar intake (in percent of energy), total fat intake (in percent of energy), pubertal stage, PAL, and parental education. Age, birth weight, and dietary variables were entered as continuous variables. Pubertal stage, PAL, and parental education were entered as dummy variables. Furthermore, we adjusted linear models by misreporting of energy intake that was estimated using the ratio between reported energy intake and predicted basal metabolic rate (EI/BMR) [4, 5, 18]. In this study, a mean PAL of 1.73 was assumed for female adolescents ages 15 to 17 years old, 1.75 for boys ages 15 to 17 years old, and 1.70 and 1.85 for girls and boys age 18 years old, respectively $[6,7]$. The thresholds that defined low-energy reporters (under-reporters) were 1.70 and 1.71 for girls and boys between 15 and 17 years old and 1.67 and 1.81 for girls and boys age 18 years. "Low-energy reporter" (a categorical variable) was included in the model as a confounding factor.

A P value of $<0.05$ was regarded as significant. All analyses were performed using PASW Statistic v.18 (SPSS, Chicago, IL, USA).

\section{Results}

Descriptive characteristics of the adolescents in the sample are shown in Table 1. The prevalence of overweight/obesity was $29.2 \%$ in boys and $32.6 \%$ in girls $(P=0.252)$. In our study, boys were more active than girls (respectively, 83.7 vs. $50.4 \%, P<0.001$ ). No significant difference was seen in the BMI and birth weight of boys compared to girls $(P>0.05$, for all). In this study, for Tanner stages, $0.7 \%$ of girls were reported to be in stage $2,18.9 \%$ in stage $3,58.7 \%$ in stage 4 , and $21.7 \%$ in stage 5 . Similar figures for boys were as follows: $0.2 \%$ in stage $1,1.2 \%$ in stage 2 , $11.2 \%$ in stage $3,57.7 \%$ in stage 4 , and $30.2 \%$ in stage 5 . 
Table 1 Characteristics of the study sample, by gender

\begin{tabular}{|c|c|c|c|}
\hline & $\begin{array}{l}\text { Girls } \\
(n=583)\end{array}$ & $\begin{array}{l}\text { Boys } \\
(n=418)\end{array}$ & $P$ value \\
\hline Age $^{\mathrm{a}, \mathrm{b}}$ (years) & $16.1 \pm 0.96$ & $16.1 \pm 0.99$ & 0.524 \\
\hline Weight $t^{a, c}(\mathrm{~kg})$ & $58.9 \pm 10.9$ & $67.8 \pm 12.9$ & $<0.001$ \\
\hline Height $^{\mathrm{a}, \mathrm{c}}(\mathrm{m})$ & $1.60 \pm 0.06$ & $1.72 \pm 0.07$ & $<0.001$ \\
\hline $\mathrm{BMI}^{\mathrm{a}, \mathrm{c}}\left(\mathrm{kg} / \mathrm{m}^{2}\right)$ & $22.9 \pm 3.8$ & $22.9 \pm 4.0$ & 0.983 \\
\hline $\mathrm{BMI}^{\mathrm{d}}(\%)$ & & & 0.252 \\
\hline Normal & 67.4 & 70.8 & \\
\hline Overweight/obese & 32.6 & 69.1 & \\
\hline Body fat ${ }^{\mathrm{a}}(\%)$ & $26.3 \pm 6.7$ & $14.7 \pm 6.8$ & $<0.001$ \\
\hline Birth weight ${ }^{\mathrm{a}, \mathrm{c}}(\mathrm{kg})$ & $3.253 \pm 0.564$ & $3.302 \pm 0.607$ & 0.191 \\
\hline $\begin{array}{l}\text { Parental education }{ }^{\mathrm{d}}(\%) \\
\text { Mandatory or less }\end{array}$ & 50.2 & 46.5 & 0.518 \\
\hline Secondary & 34.8 & 37.6 & \\
\hline College/university & 15.0 & 15.9 & \\
\hline Smoking status ${ }^{\mathrm{d}}(\%)$ & & & 0.564 \\
\hline Nonsmoker & 88.3 & 86.1 & \\
\hline Former smoker & 5.0 & 6.2 & \\
\hline Occasional/current smoker & 6.7 & 7.7 & \\
\hline $\mathrm{PA}^{\mathrm{d}}(\%)$ & & & $<0.001$ \\
\hline Low-active ( $\leq 12.5$ points) & 49.6 & 16.3 & \\
\hline Active ( $>12.5$ points) & 50.4 & 83.7 & \\
\hline
\end{tabular}

$B M I$ body mass index

${ }^{\mathrm{a}}$ Mean \pm standard deviation

${ }^{\mathrm{b}}$ Between-gender analysis by Mann-Whitney test

'Analysis by Student's $t$ test for continuous variables

${ }^{\mathrm{d}}$ Analysis by chi-square test for categorical variables

Energy intake and dietary characteristics for each gender are presented in Table 2. Boys' diets were higher in energy, total fat, total dairy, milk, and calcium intake and lower in carbohydrates and dietary fiber, compared to girls $(P<0.05$, for all). There was no significant difference between boys and girls with regard to protein, sugar, yogurt, and cheese intake. 
Table 2 Dietary characteristics of the study sample, by gender

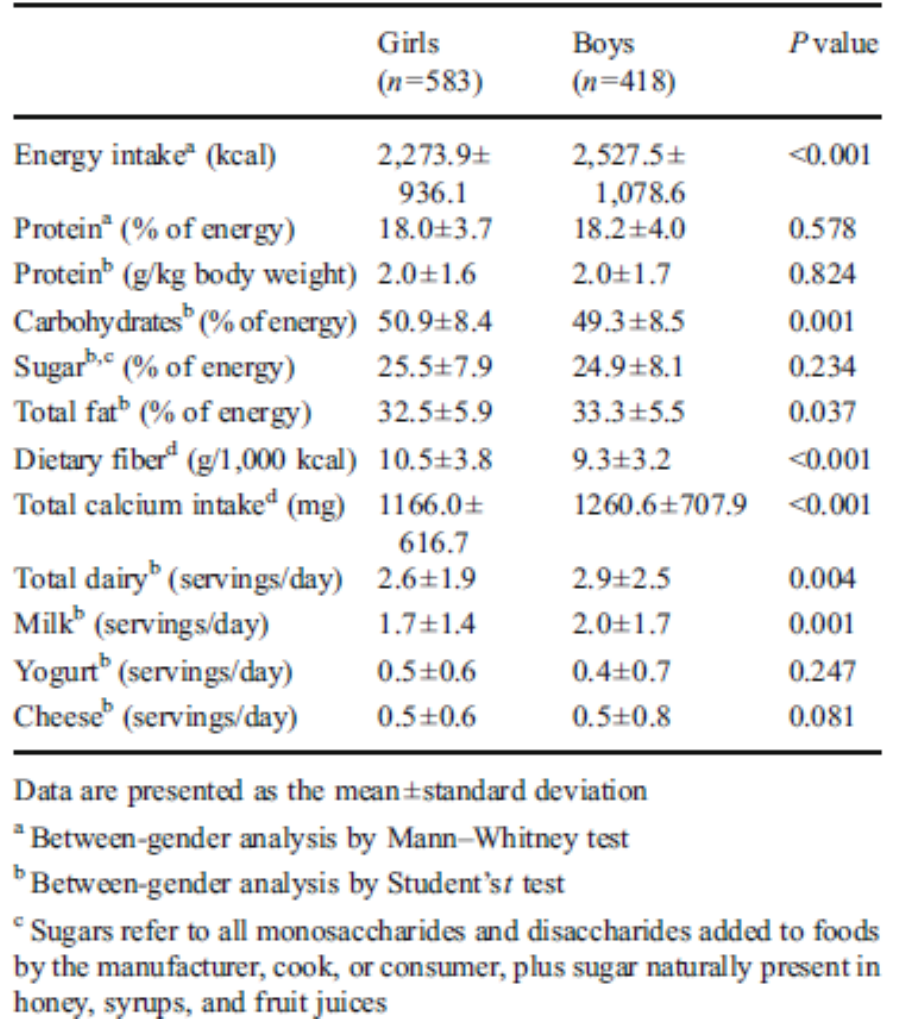

The results of the linear regression analyses used to estimate the association between DP intake and both BMI and \%BF are presented in Table 3. After adjusting for age, birth weight, pubertal stage, dietary factors, parental education, and PAL (model 2), linear regression showed that milk intake was negatively and significantly associated with $\mathrm{BMI}$ and \% $\mathrm{BF}$ only in girls (respectively, girls: $\beta=-0.167, P=0.013$; boys: $\beta=-0.019, P=0.824$ and girls: $\beta=-0.143, P=0.030$; boys: $\beta=-0.051, P=0.548$.

Table 3 Association between DP intake and both BMI and \%BF, using separate linear regression models for total dairy, milk, yogurt, and cheese intakes (servings/day), by gender

\begin{tabular}{|c|c|c|c|c|c|c|c|c|c|c|c|c|}
\hline & \multicolumn{6}{|c|}{ BMI $\left(\mathrm{kg} / \mathrm{m}^{2}\right)$} & \multicolumn{6}{|l|}{ BF (\%) } \\
\hline & \multicolumn{3}{|c|}{ Girls $(n=583)$} & \multicolumn{3}{|c|}{ Boys $(n=418)$} & \multicolumn{3}{|c|}{ Girls $(n=583)$} & \multicolumn{3}{|c|}{ Boys $(n=418)$} \\
\hline & $\beta$ & $95 \%$ CI & $P$ value & $\beta$ & $95 \% \mathrm{CI}$ & $P$ value & $\beta$ & $95 \% \mathrm{CI}$ & $P$ value & $\beta$ & $95 \% \mathrm{CI}$ & $P$ value \\
\hline \multicolumn{13}{|l|}{ Model 1} \\
\hline Total dairy & -0.065 & $-0.245,0.004$ & 0.057 & -0.008 & $-0.150,0.124$ & 0.854 & -0.055 & $-0.409,0.041$ & 0.109 & 0.008 & $-0.213,0.262$ & 0.837 \\
\hline Milk & -0.092 & $\begin{array}{l}-0.406 \\
-0.065\end{array}$ & 0.007 & -0.033 & $-0.272,0.114$ & 0.421 & -0.074 & $\begin{array}{l}-0.651, \\
-0.033\end{array}$ & 0.030 & -0.025 & $-0.436,0.232$ & 0.547 \\
\hline Yogurt & -0.002 & -0.416 .0 .395 & 0.960 & -0.023 & $-0.659,0.371$ & 0.582 & -0.014 & $-0.881,0.581$ & 0.687 & 0.018 & $-1.087,0.695$ & 0.666 \\
\hline Cheese & -0.004 & $-0.511,0.465$ & 0.926 & 0.010 & $-0.449,0.553$ & 0.858 & 0.010 & $-0.567,0.776$ & 0.760 & 0.090 & $0.083,1.467$ & 0.028 \\
\hline \multicolumn{13}{|l|}{ Model 2} \\
\hline Total dairy & -0.213 & $-0.913,0.100$ & 0.113 & -0.021 & $-0.512,0.444$ & 0.890 & -0.171 & $-1.498,0.302$ & 0.192 & 0.082 & $-0.607,1.063$ & 0.591 \\
\hline Milk & -0.167 & $\begin{array}{c}-0.770 \\
-0.089\end{array}$ & 0.013 & -0.019 & $-0.421,0.335$ & 0.824 & -0.143 & $\begin{array}{r}-1.245 \\
-0.062\end{array}$ & 0.030 & -0.051 & $-0.862,0.458$ & 0.548 \\
\hline Yogurt & 0.056 & $-0.246,0.976$ & 0.241 & 0.042 & $-0.437,0.952$ & 0.467 & 0.035 & $-0.654,1.470$ & 0.451 & 0.026 & $-0.935,1.493$ & 0.652 \\
\hline Cheese & 0.055 & $-0.206,0.870$ & 0.226 & -0.029 & $-0.772,0.476$ & 0.641 & 0.062 & $-0.274,1.594$ & 0.166 & 0.080 & $-0.374,1.803$ & 0.198 \\
\hline
\end{tabular}

Model 1 is the unadjusted model. Model 2 is adjusted for age (years), birth weight (kilograms), energy intake (kilocalories), protein intake (grams per kilogram body weight), total fat intake (percent of energy), sugar intake (percent of energy), total calcium intake (milligrams), parental education, low-energy reporters, pubertal stage, and PAL

$B M I$ body mass index, $B F$ body fat, $C I$ confidence interval 


\section{Discussion}

The present study explored the relationship between DP (total, milk, yogurt, and cheese) intake and $\mathrm{BMI}$ and \%BF among adolescents. The results suggested that intake of milk was negatively associated with $\mathrm{BMI}$ and \%BF only in girls. The associations identified were not confounded by other lifestyle factors or dietary variables, particularly calcium intake.

The literature related to DP intake, especially different types of dairy (such as milk, yogurt, and cheese) and overweight/obesity in adolescents is limited and conflicting. Data from crosssectional epidemiological studies support the hypothesis that milk and/or dairy consumption is associated with lower body fat and BMI in children and adolescents $[1,17,31,36,37]$. Moore et al. [31] found that adolescents in the lowest category of total dairy intake had higher BMIs and more subcutaneous fat in their subscapular and triceps skinfolds. However, in their analysis, this association was not explored with different types of DP, as were the associations in our study. In addition, Barba et al. [1] found a significant inverse association between frequency of milk consumption and BMI in children. In adults, a cross-sectional survey carried out with a large sample of the Portuguese population showed that milk intake was inversely related to BMI in men and premenopausal women [30].

Nevertheless, prospective studies have yielded inconsistent results. Johnson et al. [26] found that each serving of milk at 5 and 7 years of age was associated with a decrease in \%BF at 9 years of age. A recent study also found that higher intake of whole milk at 2 years of age was associated with a decrement in BMI z-score at 3 years of age; however, when analysis was restricted to children with normal BMI (5th to <85th percentile for age), this association disappeared [23]. One study found that children who reported higher total milk intake experienced larger BMI gains, although this appeared to be mediated by energy intake [2]. However, this association was stronger for skim and $1 \%$ milk intake than for whole or $2 \%$ milk. In our study, we did not separate high-fat milk from low-fat milk, but we did control for the effects of fat intake.

Controlled intervention studies have also examined the relationship between dairy and/or milk consumption and fatness or body weight. Chan et al. [9] reported that, when 50 children with low calcium intake ( $<800 \mathrm{mg}$ daily) were allocated to either a dairy-supplemented group or a control group for 6 months, children in the control group gained body fat during the study, while children in the dairy group had no significant change in body fat. On the other hand, in a randomized controlled trial that evaluated whether high milk (4 servings/day) consumption leads to greater weight loss in overweight children than low milk (1 serving/day) consumption during the course of a 16-week healthy-eating diet, St-Onge et al. [48] observed no significant differences between the groups in weight loss. Numerous intervention trials have been conducted in adults, and their findings are also conflicting. Of 11 studies without energy restrictions that were reviewed by Dougkas et al. [16], 7 reported no significant difference in weight or body fat with milk supplementation or dairy treatment, 2 reported weight gain, and 2 found higher body fat loss in groups with dairy-rich diets.

Our results showed no significant association between yogurt and cheese intake and BMI and $\% B F$. In the literature, the majority of studies have examined milk intake, while only a few have used other dairy foods as the exposure variable. The weight of evidence suggests that milk intake is more likely to be associated with beneficial weight and body fat outcome $[1,26,28,38,48]$, while a very small number of studies, conducted only with adults, have shown the beneficial effects of such other DPs as yogurt and cheese $[3,46,56]$. 
Discrepancies in the findings of existing studies could be due to differences in study design, methods for assessing diet and body composition (dual-energy X-ray absorptiometry [DXA] vs. BIA), treatment of milk and dairy intake (servings/day, grams, consumers vs. nonconsumers), adjustment of potentially confounding factors during analysis and/or due to the complexity of interactions between nutrients in humans $[21,36]$. The inclusion of misreported dietary intakes may also lead to inconsistent findings; indeed, such misreporting is common in dietary studies $[8,20,22]$. Huang et al. [20] noted that underreporting is a major problem with adolescents, whereas overreporting is a significant problem with children under 12 years of age. In addition, Ventura et al. [55] found that under-reporters were selective in their underreporting, reporting fewer servings from the grain, dairy, sweets, and fats groups. In light of these findings, we did control for the effects of underreporting in our study.

In the present study, we found a significant and inverse association between milk intake and $\mathrm{BMI}$ and \%BF only in girls. Another study has also found the same association [38]. Overall, the evidence suggests that gender may influence body composition, with girls having greater \%BF $[12,51]$. We cannot exclude the hypothesis that the interaction between DPs (and its components) and weight and body fat may differ across different thresholds of \%BF [32]. For instance, Vergnaud et al. [56] reported that milk and yogurt intake were protective against 6year changes in body weight only in adults who were initially overweight. In line with this, dos Santos et al. [15] found a negative relationship between calcium intake and body trunk fat only in obese adolescents. However, in our study, DPs (total, milk, yogurt, and cheese) consumption was not associated with \% BF when normal weight and overweight/obese adolescents were considered separately (data not shown). Furthermore, the dynamic metabolic changes that occur during growth and puberty may complicate the interaction between DPs and weight and body fat [21]. Nevertheless, this study addressed sexual maturation, controlling for the extent of biological growth and the individual nutritional needs of adolescents [47]. Although no inverse association was found in boys, consumption of DPs did not increase the probability of being obese, as other studies had reported $[2,23,36]$. It is noteworthy that DPs are widely recognized as good sources of nutrients in the adolescents' diet as they are important to in the promotion of bone and overall health [54].

Several mechanisms were proposed to explain how DP might influence energy balance and body composition. DPs are an important source of calcium, which appears to play a significant role in the regulation of energy metabolism by reduction of lipogenesis and enhancement of lipolysis on adipocyte, increasing both fecal fat excretion and fat oxidation [16]. In the present study, however, we found a significant association only for milk consumption, even after adjusting for calcium, and other plausible mechanisms should be taken into account. Recently, it has been suggested that milk is rich in bioactive peptides (whereas other DPs contain little or no such substances) that may also act independently of calcium to modulate body fat accumulation [40, 45]. Milk bioactive peptides (casokinins and lactokinins) have been shown to inhibit angiotensinconverting enzyme and, consequently, to inhibit the production of angiotensin II hormone, which has been reported to upregulate adipocyte lipogenesis, resulting in the inhibition of fat deposition [61]. In addition, Strazzullo et al. [49] showed, in a prospective study with adult men, that carriers of the DD variant of the angiotensin-converting enzyme gene (associated with higher plasma levels of angiotensin-converting enzyme activity) reported a higher incidence of overweight. Milk, especially whey protein, also stimulates insulin secretion that may directly affect food intake regulation by suppressing appetite, independent of the effects of dietary Ca $[27,35]$. Yet, we could not exclude the possibility that milk consumption might be a marker of other healthier lifestyle traits that protect against overweight/obesity and that were not 
explored in the present study. A positive health relationship between milk intake and education may reflect a growing concern about health in the higher socioeconomic groups. However, the association between milk consumption and socioeconomic position is sometimes contradictory $[13,43]$; therefore, our results were adjusted for parental education.

Our study has some limitations. Its cross-sectional design prevents the drawing of any conclusions related to cause and effect. The measures of \%BF used in this study are also less accurate than more sophisticated measurements (i.e., DXA, computerized tomography, magnetic resonance imaging). However, BIA has been used as a simple, reliable, valid, inexpensive, portable, and quick tool to assess \%BF with large samples, and BIA has also been better correlated than anthropometric indices (BMI and weight-for-height index) in estimations of $\% \mathrm{BF}[53]$.

In conclusion, we found an inverse association between milk intake and BMI and \%BF in girls. Further studies are needed on the roles that diet and healthy lifestyles play in the interaction between DPs and body composition. Our findings may also encourage further research on the effects of a threshold BF and sex hormone effects explaining the difference between girls and boys as well as the influence of additional dairy components, such as whey proteins.

\section{References}

1. Barba G, Troiano E, Russo P, Venezia A, Siani A (2005) Inverse association between body mass and frequency of milk consumption in children. Br J Nutr 93:15-19

2. Berkey CS, Rockett HR, Willett WC, Colditz GA (2005) Milk, dairy fat, dietary calcium, and weight gain: a longitudinal study of adolescents. Arch Pediatr Adolesc Med 159:543-550

3. Beydoun MA, Gary TL, Caballero BH, Lawrence RS, Cheskin LJ, Wang Y (2008) Ethnic differences in dairy and related nutrient consumption among US adults and their association with obesity, central obesity, and the metabolic syndrome. Am J Clin Nutr 87:1914-1925

4. Black $A E$ (2000) Critical evaluation of energy intake using the Goldberg cut-off for energy intake:basal metabolic rate. A practical guide to its calculation, use and limitations. Int J Obes Relat Metab Disord 24:1119-1130

5. Black AE (2000) The sensitivity and specificity of the Goldberg cut-off for El:BMR for identifying diet reports of poor validity. Eur J Clin Nutr 54:395-404

6. Black AE, Coward WA, Cole TJ, Prentice AM (1996) Human energy expenditure in affluent societies: an analysis of 574 doubly-labelled water measurements. Eur J Clin Nutr 50:72-92

7. Black AE, Goldberg GR, Jebb SA, Livingstone MB, Cole TJ, Prentice AM (1991) Critical evaluation of energy intake data using fundamental principles of energy physiology: 2. Evaluating the results of published surveys. Eur J Clin Nutr 45:583-599

8. Champagne CM, Baker NB, DeLany JP, Harsha DW, Bray GA (1998) Assessment of energy intake underreporting by doubly labeled water and observations on reported nutrient intakes in children. J Am Diet Assoc 98:426-433

9. Chan GM, McNaught T (2001) The effects of dairy products on children's body fat. J Am Coll Nutr 20:577 
10. Cole TJ, Bellizzi MC, Flegal KM, Dietz WH (2000) Establishing a standard definition for child overweight and obesity worldwide: international survey. BMJ 320:1240-1243

11. Cole TJ, Flegal KM, Nicholls D, Jackson AA (2007) Body mass index cut offs to define thinness in children and adolescents: international survey. BMJ 335:194

12. Cowell CT, Briody J, Lloyd-Jones S, Smith C, Moore B, Howman-Giles R (1997) Fat distribution in children and adolescents - the influence of sex and hormones. Horm Res 48(Suppl 5):93-100

13. Cristofar SP, Basiotis PP (1992) Dietary intakes and selected characteristics of women ages 19-50 years and their children ages $1-5$ years by reported perception of food sufficiency. J Nutr Educ 24:53-58

14. de Ferranti S, Mozaffarian D (2008) The perfect storm: obesity, adipocyte dysfunction, and metabolic consequences. Clin Chem 54:945-955

15. dos Santos LC, de Padua Cl, Fisberg M, Martini LA (2008) Calcium intake and its relationship with adiposity and insulin resistance in post-pubertal adolescents. J Hum Nutr Diet 21:109-116

16. Dougkas A, Reynolds CK, Givens ID, Elwood PC, Minihane AM (2011) Associations between dairy consumption and body weight: a review of the evidence and underlying mechanisms. Nutr Res Rev 24:72-95

17. Fiorito LM, Ventura AK, Mitchell DC, Smiciklas-Wright H, Birch LL (2006) Girls' dairy intake, energy intake, and weight status. J Am Diet Assoc 106:1851-1855

18. Goldberg GR, Black AE, Jebb SA, Cole TJ, Murgatroyd PR, Coward WA, Prentice AM (1991) Critical evaluation of energy intake data using fundamental principles of energy physiology: 1. Derivation of cut-off limits to identify under-recording. Eur J Clin Nutr 45:569-581

19. Guo SS, Wu W, Chumlea WC, Roche AF (2002) Predicting overweight and obesity in adulthood from body mass index values in childhood and adolescence. Am J Clin Nutr 76:653658

20. Huang TT, Howarth NC, Lin BH, Roberts SB, McCrory MA (2004) Energy intake and meal portions: associations with BMI percentile in U.S. children. Obes Res 12:1875-1885

21. Huang TT, McCrory MA (2005) Dairy intake, obesity, and metabolic health in children and adolescents: knowledge and gaps. Nutr Rev 63:71-80

22. Huang TT, Roberts SB, Howarth NC, McCrory MA (2005) Effect of screening out implausible energy intake reports on relationships between diet and BMI. Obes Res 13:1205-1217

23. Huh SY, Rifas-Shiman SL, Rich-Edwards JW, Taveras EM, Gillman MW (2010) Prospective association between milk intake and adiposity in preschool-aged children. J Am Diet Assoc 110:563-570

24. Instituto Nacional Estatística (2003) Estimativas da População Residente, segundo Grandes Grupos Etários e Sexo 
25. International Association for the Study of Obesity (2011) Childhood and adolescent overweight in Europe. Available at http://www.iaso.org/publications/trackingobesity/underdata-down-loads/

26. Johnson L, Mander AP, Jones LR, Emmett PM, Jebb SA (2007) Is sugar-sweetened beverage consumption associated with increased fatness in children? Nutrition 23:557-563

27. Layman DK, Shiue H, Sather C, Erickson DJ, Baum J (2003) Increased dietary protein modifies glucose and insulin homeostasis in adult women during weight loss. J Nutr 133:405-410

28. Louie JC, Flood VM, Hector DJ, Rangan AM, Gill TP (2011) Dairy consumption and overweight and obesity: a systematic review of prospective cohort studies. Obes Rev 12:e582-592

29. Maffeis C (2000) Aetiology of overweight and obesity in children and adolescents. Eur J Pediatr 159(Suppl 1):S35-44

30. Marques-Vidal P, Goncalves A, Dias CM (2006) Milk intake is inversely related to obesity in men and in young women: data from the Portuguese Health Interview Survey 1998-1999. Int J Obes (Lond) 30:88-93

31. Moore LL, Singer MR, Qureshi MM, Bradlee ML (2008) Dairy intake and anthropometric measures of body fat among children and adolescents in NHANES. J Am Coll Nutr 27:702-710

32. Moreira P, Padez C, Mourao I, Rosado V (2005) Dietary calcium and body mass index in Portuguese children. Eur J Clin Nutr 59:861-867

33. Mota J, Esculcas C (2002) Leisure-time physical activity behavior: structured and unstructured choices according to sex, age, and level of physical activity. Int J Behav Med 9:111121

34. Must A, Spadano J, Coakley EH, Field AE, Colditz G, Dietz WH (1999) The disease burden associated with overweight and obesity. JAMA 282:1523-1529

35. Nilsson M, Holst JJ, Bjorck IM (2007) Metabolic effects of amino acid mixtures and whey protein in healthy subjects: studies using glucose-equivalent drinks. Am J Clin Nutr 85:996-1004

36. Noel SE, Ness AR, Northstone K, Emmett P, Newby PK (2011) Milk intakes are not associated with percent body fat in children from ages 10 to 13 years. J Nutr 141:2035-2041

37. Novotny R, Acharya S, Grove JS, Daida YG, Vogt TM (2003) Higher dairy intake is associated with lower body fat during adolescence. FASEB J 18:A2277

38. Novotny R, Daida YG, Acharya S, Grove JS, Vogt TM (2004) Dairy intake is associated with lower body fat and soda intake with greater weight in adolescent girls. J Nutr 134:1905-1909

39. Parsons TJ, Power C, Logan S, Summerbell CD (1999) Childhood predictors of adult obesity: a systematic review. Int J Obes Relat Metab Disord 23(Suppl 8):S1-107

40. Pihlanto-Leppala A, Koskinen P, Piilola K, Tupasela T, Korhonen H (2000) Angiotensin Iconverting enzyme inhibitory properties of whey protein digests: concentration and characterization of active peptides. J Dairy Res 67:53-64 
41. Ramos E (2006) Health determinants in Porto adolescents-the Epiteen Cohort. Ph.D. thesis, University of Porto, Porto

42. Rodrigues SS, Franchini B, Graca P, de Almeida MD (2006) A new food guide for the Portuguese population: development and technical considerations. J Nutr Educ Behav 38:189195

43. Roos E, Prattala R, Lahelma E, Kleemola P, Pietinen P (1996) Modern and healthy?: socioeconomic differences in the quality of diet. Eur J Clin Nutr 50:753-760

44. Sardinha LB, Santos R, Vale S, Silva AM, Ferreira JP, Raimundo AM, Moreira H, Baptista F, Mota J (2011) Prevalence of overweight and obesity among Portuguese youth: a study in a representative sample of 10-18-year-old children and adolescents. Int J Pediatr Obes 6:e124128

45. Shah NP (2000) Effects of milk-derived bioactives: an overview. Br J Nutr 84(Suppl 1):S3-10

46. Snijder MB, van der Heijden AA, van Dam RM, Stehouwer CD, Hiddink GJ, Nijpels G, Heine RJ, Bouter LM, Dekker JM (2007) Is higher dairy consumption associated with lower body weight and fewer metabolic disturbances? The Hoorn Study. Am J Clin Nutr 85:989-995

47. Stang J, Story M (eds) (2005) Adolescent growth and development. Guidelines for adolescent nutrition services. Center for Leadership, Education and Training in Maternal and Child Nutrition, Division of Epidemiology and Community Health, School of Public Health, University of Minnesota, Minneapolis, MN, pp 1-8

48. St-Onge MP, Goree LL, Gower B (2009) High-milk supplementation with healthy diet counseling does not affect weight loss but ameliorates insulin action compared with low-milk supplementation in overweight children. J Nutr 139:933-938

49. Strazzullo P, lacone R, lacoviello L, Russo O, Barba G, Russo P, D'Orazio A, Barbato A, Cappuccio FP, Farinaro E, Siani A (2003) Genetic variation in the renin-angiotensin system and abdominal adiposity in men: the Olivetti Prospective Heart Study. Ann Intern Med 138:17-23

50. Tanner JM, Whitehouse RH (1976) Clinical longitudinal standards for height, weight, height velocity, weight velocity, and stages of puberty. Arch Dis Child 51:170-179

51. Taylor RW, Jones IE, Williams SM, Goulding A (2002) Body fat percentages measured by dualenergy X-ray absorptiometry corresponding to recently recommended body mass index cutoffs for overweight and obesity in children and adolescents aged 3-18 y. Am J Clin Nutr 76:14161421

52. Telama R, Yang X, Laakso L, Viikari J (1997) Physical activity in childhood and adolescence as predictor of physical activity in young adulthood. Am J Prev Med 13:317-323

53. Tyrrell VJ, Richards G, Hofman P, Gillies GF, Robinson E, Cutfield WS (2001) Foot-to-foot bioelectrical impedance analysis: a valuable tool for the measurement of body composition in children. Int J Obes Relat Metab Disord 25:273-278

54. US Department of Agriculture, US Department of Health and Human Services (2010) Dietary guidelines for Americans, 2010. US Government Printing Office, Washington, DC 
55. Ventura AK, Loken E, Mitchell DC, Smiciklas-Wright H, Birch LL (2006) Understanding reporting bias in the dietary recall data of 11-year-old girls. Obesity (Silver Spring) 14:1073-1084

56. Vergnaud AC, Peneau S, Chat-Yung S, Kesse E, Czernichow S, Galan P, Hercberg S, Bertrais S (2008) Dairy consumption and 6-y changes in body weight and waist circumference in middleaged French adults. Am J Clin Nutr 88:1248-1255

57. Wang $\mathrm{Y}$, Lobstein $\mathrm{T}$ (2006) Worldwide trends in childhood overweight and obesity. Int J Pediatr Obes 1:11-25

58. Willett W (1998) Food frequency methods. Nutritional epidemiology. Oxford University Press, New York, pp 74-100

59. World Health Organization (1998) Guidelines for controlling and monitoring the Tobacco Epidemic. WHO, Geneva

60. World Health Organization (2011) Global health observatory data repository. WHO, Geneva

61. Zemel MB (2005) The role of dairy foods in weight management. J Am Coll Nutr 24:537S$546 \mathrm{~S}$ 